\title{
Potassium Aminosalicylate
}

National Cancer Institute

\section{Source}

National Cancer Institute. Potassium Aminosalicylate. NCI Thesaurus. Code C47678.

The potassium salt form of aminosalicylic acid, an analog of aminobenzoic acid used to treat tuberculosis. Although the mechanism of action of potassium aminosalicylate remains to be elucidated, its effects on mycobacteria may be attributed to inhibition of folic acid or mycobactin (cell wall component) synthesis. This agent also inhibits the onset of drug resistance to streptomycin and isoniazid. 